\title{
Evaluating uncertainty in measurements of fish shoal aggregate backscattering cross-section caused by small shoal size relative to beam width
}

\author{
Noël Diner ${ }^{\mathrm{a}}$ \\ Ifremer Centre de Brest, BP 70, 29280 Plouzané, France
}

Received 16 April 2007; Accepted 21 May 2007

\begin{abstract}
The aggregate backscattering cross-section, $\sigma_{\mathrm{ag}}$, is the sum of backscattering cross-sections of all fish in a shoal. It is a basic acoustical parameter used for shoal description and biomass estimation. Simulations were undertaken for evaluating the impact of horizontal dimension, density, depth and beam width on measurements of $\sigma_{\mathrm{ag}}$ for shoals with constant abundance. The important factor determining measurement bias is the ratio of shoal size expressed as along cross-section length relative to along ship beam width at mean shoal depth. The results show that $10 \log _{10}\left(\sigma_{\mathrm{ag}}\right)$ is underestimated by about $8 \mathrm{~dB}$ for a $5 \mathrm{~m}$ long shoal located at $200 \mathrm{~m}$ depth if detected by a $7^{\circ}$ beam. A formula for correcting $\sigma_{\mathrm{ag}}$ estimates for shoal sizes bigger than 1.3 times the beam width is proposed. The negative measurement bias can also be reduced by using transducers with narrower beam widths.
\end{abstract}

Key words: Bias / Accuracy / Acoustic measurements / Single beam echosounder / Shoal energy / Shoal dimension

Résumé - Evaluation de l'incertitude des mesures de l'énergie agrégée des bancs de poissons occasionnée par la petite taille des bancs relative à la taille du faisceau acoustique. L'énergie agrégée d'un banc, $\sigma_{\mathrm{ag}}$, est définie comme la somme des énergies réfléchies par tous les poissons du banc. C'est un paramètre fondamental de l'acoustique halieutique pour la description de la géométrie des bancs et pour l'estimation de la biomasse. Une étude de simulation a été menée pour évaluer l'impact de la taille horizontale d'un banc, sa densité et profondeur et l'ouverture du faisceau sur les mesures de $\sigma_{\text {ag }}$ pour des bancs d'abondance constante. Le facteur déterminant du biais de mesure est le rapport entre la longueur du banc et la taille du faisceau à la profondeur moyenne du banc. Les résultats montrent que 10 $\log _{10}\left(\sigma_{\mathrm{ag}}\right)$ est sous-estimé de $8 \mathrm{~dB}$ pour un banc de longueur de $5 \mathrm{~m}$ à $200 \mathrm{~m}$ de profondeur si le banc est mesuré par un faisceau d'ouverture angulaire de $7^{\circ}$. Une formule est proposée pour corriger les estimations de $\sigma_{\text {ag }}$ pour les bancs de longueur au moins 1,3 fois plus grande que la taille du faisceau. Le biais négatif de mesures peut aussi être diminué par l'utilisation de sondeurs de meilleure résolution angulaire.

\section{Introduction}

Echo-integration is the common method for abundance and biomass estimation based on acoustic measurements (Simmonds and MacLennan 2005). In the case of fish occurring in shoals, the integration amounts to summing the backscattering strength of all shoals detected within a given survey transect, e.g. a nautical mile. The aggregate backscattering cross-section of a single shoal, denoted $\sigma_{\mathrm{ag}}$, is therefore an important parameter and any bias in its measurement will lead to biased density and abundance estimates. As demonstrated by Diner (2001), shoal length is overestimated due to border effects created by the finite beam width, hence it can be expected that measurements of $\sigma_{\mathrm{ag}}$ are also biased, but this time underestimated. Muiño et al. (2003) observed an unexplained

\footnotetext{
${ }^{a}$ Revised version prepared by Verena Trenkel, Ifremer, BP 21105, 44311 Nantes Cedex 3, France e-mail: Verena.Trenkel@ifremer.fr
}

negative relationship between shoal energy and shoal depth across several species and study areas. This pattern might be, at least partially, explained by an underestimation of shoal density as a function of shoal depth. The physical reasons for the expected biased measurements of $\sigma_{\mathrm{ag}}$ are explained below and the order of magnitude of measurement bias is explored using simulations.

Using standard notation proposed by MacLennan et al. (2002) the aggregate backscattering cross-section of a shoal is defined as:

$$
\sigma_{\mathrm{ag}}=\sum^{\sigma_{\mathrm{bs}}}
$$

where $\sigma_{\mathrm{bs}}$ is the backscattering cross-section of an individual target (fish) and the sum is over all targets in the entire volume of the shoal intercepted by the sound beam, that is, it includes all echoes received from the shoal. Based on fish density $\rho$ inside the shoal, $\sigma_{\text {ag }}$ can be expressed as

$$
\sigma_{\mathrm{ag}}=\sigma_{\mathrm{bs}} \rho V
$$




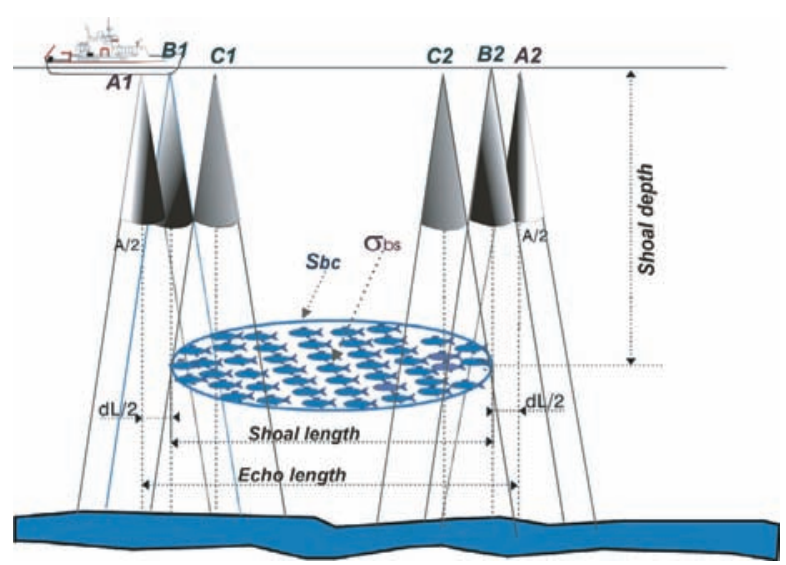

Fig. 1. Diagram in vertical plane of the process of shoal detection by a vertical echosounder.

where $V$ is the total sampled volume of the shoal. However, this equation does not account for the border effect occurring at the beginning and at the end of shoal detection. That is, when the sound beam is not completely occupied by targets, the calculated (sampling) volume $V$ is bigger than the actual shoal volume. The border effect can be seen clearly when decomposing the shoal detection by a vessel-mounted vertical echo sounder into three phases (Figs. 1 and 2):

- C1C2: the beam is fully occupied by the targets; the shoal cross-section surface $S_{\mathrm{bc}}$ and $\sigma_{\mathrm{bs}}$ are measured without bias;

- B1C1 (and C2B2): the beam axis is inside the shoal and the targets partially occupy the beam; $S_{\mathrm{bc}}$ is unbiased, but $\sigma_{\text {bs }}$ is underestimated; and

- A1B1 (and B2A2): the beam axis is outside the shoal and the targets partially occupy the beam; $S_{\mathrm{bc}}$ and $\sigma_{\mathrm{bs}}$ are overestimated due to extrapolation of shoal biomass outside the actual shoal limits.

The data gathered during A1B1 (and B2A2) generally do not compensate perfectly for the underestimation of phase B1C1 (and C2B2). Near perfect compensation occurs when the shoal has very large horizontal shoal dimensions compared to the beam, i.e. when the circle arc FB1F' (Fig. 2b) is close to a straight line.

Thus, underestimation of $\sigma_{\mathrm{ag}}$ by a vertical echo sounder can have two origins: i) shoals with small horizontal dimensions only partially occupy the beam; ii) shoals fully occupy the beam, but have curved edges, not allowing a perfect compensation of underestimation "B1C1" by the complementary data gathered during phase "A1B1".

Given the expected underestimation of $\sigma_{\mathrm{ag}}$ for small shoals, it seems important to first determine the magnitude of the problem and then explore the possibility of deriving an empirical correction formula. When designing an algorithm for the correction of echo trace descriptors (Diner 2001), the relative length of the shoal compared to the beamwidth at the mean depth of the shoal, called $N b_{i}$, was identified as the key parameter. It is calculated using the real detection angle, and allows correction of the measured shoal length though only if $N b_{i}>1.5$; for smaller ratios no correction can be carried out. a)

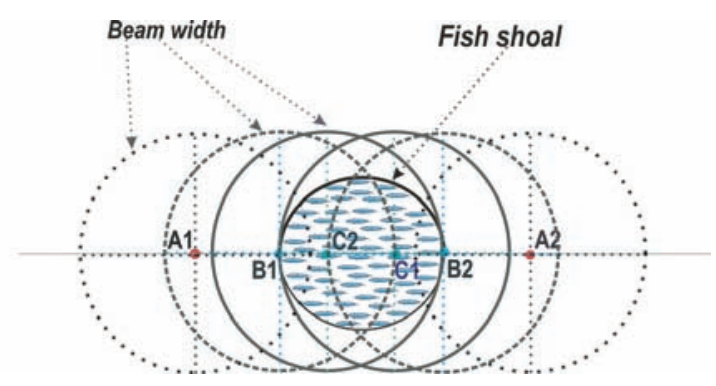

b)

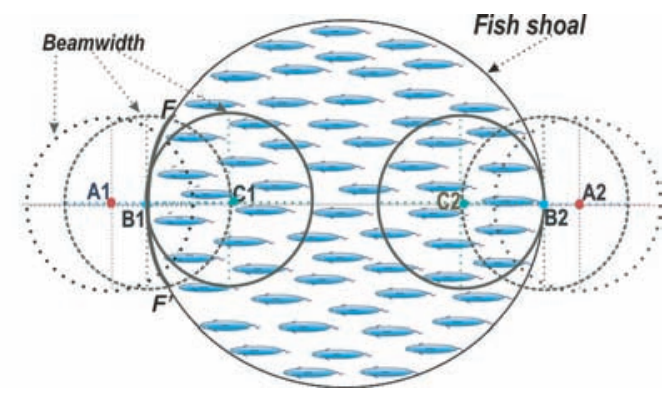

Fig. 2. Diagram in horizontal plane of the process of a shoal detection by a vertical echosounder. a) shoal size is smaller than the beam; b) shoal size is larger than the beam.

As for correcting shoal length, $N b_{i}$ is expected to be the key parameter for correcting $\sigma_{\text {ag }}$ measurements.

The detection of a fish shoal by a vertical sounder is a complex process. Simulations allow the process to be analysed in detail, thereby highlighting sensitivities and quantifying likely problems. In addition, true values are known allowing quantification of measurement bias. In this paper, the magnitude of measurement bias of $\sigma_{\mathrm{ag}}$ is estimated based on several simulation scenarios. Finally, an empirical correction formula is derived.

\section{Methods}

Four simulation scenarios of fish shoals and acoustic measurements were carried out using the acoustic data simulator OASIS (V. Mazauric, pers. comm. for an updated version of the simulator used by Diner 2003). The scenarios are summarised in Table 1. For all scenarios, shoals of various dimensions were placed at different depths between 50 and $200 \mathrm{~m}$. Shoal widths and length were equal in all cases and shoal volume is calculated for an elliptical body.

For scenario 1, single shoals of variable horizontal shoal dimensions and density but approximately the same number of targets per shoal were simulated (Table 2, Fig. 3). For scenario 2, shoal density was kept constant and only horizontal shoal dimensions varied (Table 3, Fig. 4). The number of shoals was set as to fix the total number of fish. Scenario 3 was identical to scenario 2 , the only difference being the smaller beam width used, $2^{\circ}$ and $3^{\circ}$ instead of $7^{\circ}$. Figure 5 shows the simulated shoals. For the final scenario 4, a new range of shoals were simulated to study the relationship between 
Table 1. Characteristics of simulation scenarios.

\begin{tabular}{lllll}
\hline Scenario & 1 & 2 & 3 & 4 \\
\hline Number of targets & constant & variable & variable & variable \\
Number of shoals & 1 & $>1$ & $>1$ & $>1$ \\
Shoal density & variable & constant & constant & constant \\
Horizontal shoal dimension $(\mathrm{m})$ & $5-200$ & $4-75$ & $4-75$ & $4-30$ \\
Vertical shoal dimension $(\mathrm{m})$ & 5 & 5 & 5 & 5 \\
Shoal depth $(\mathrm{m})$ & $50,100,200$ & $50,100,200$ & $50,100,150,200$ & $50,100,150,200$ \\
Beam width $\left({ }^{\circ}\right)$ & 7 & 7 & 2,3 & $2,3,4,7$ \\
Target strength $(\mathrm{dB})$ & -40 & -40 & -40 & -40 \\
Signal threshold $(\mathrm{dB})$ & -70 & -60 & -50 & -60 \\
\hline
\end{tabular}

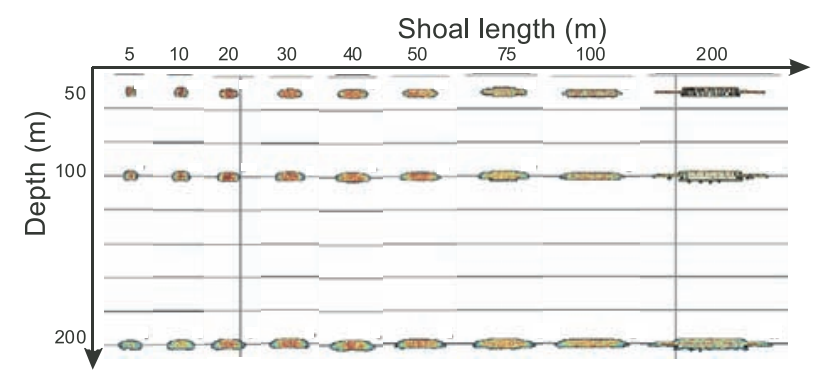

Fig. 3. Echograms of simulated shoals for scenario 1.

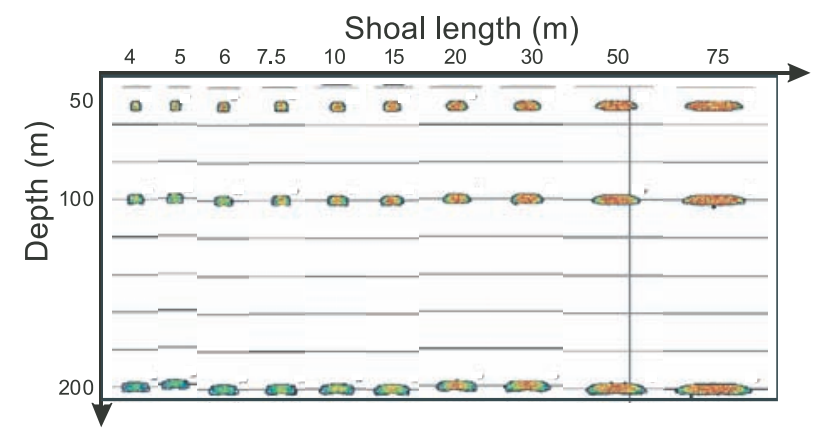

Fig. 4. Echograms of simulated shoals for scenario 2.

relative shoal length with respect to beam width for four different beam widths. To get more precise measurements of shoal echo length, and thus the $N b_{i}$ factor, vessel speed and ping rate were adjusted so as to oversample longitudinally (at least 20 pings per shoal for the smallest shoals).

For all simulated acoustic shoals, $\sigma_{\text {ag }}$ was estimated using the shoal echo-integration option of the MOVIES+ software (Diner et al. 2003; Weill et al. 1993). For comparing simulated measures to true values, the estimation bias of the logarithmic measure of $\sigma_{\mathrm{ag}}$ was chosen, which could be called shoal backscattering strength, as it has the interpretable units $\mathrm{dB}$,

$$
\varepsilon=\log _{10}\left(\hat{\sigma}_{\mathrm{ag}}\right)-10 \log _{10}\left(\sigma_{\mathrm{ag}}\right)
$$

where $\hat{\sigma}_{\text {ag }}$ is the estimate from the simulated shoal image, and $\sigma_{\text {ag }}$ is the true value.

\section{Results}

For scenario 1, with single shoals of different sizes and densities but the same number of targets placed at different

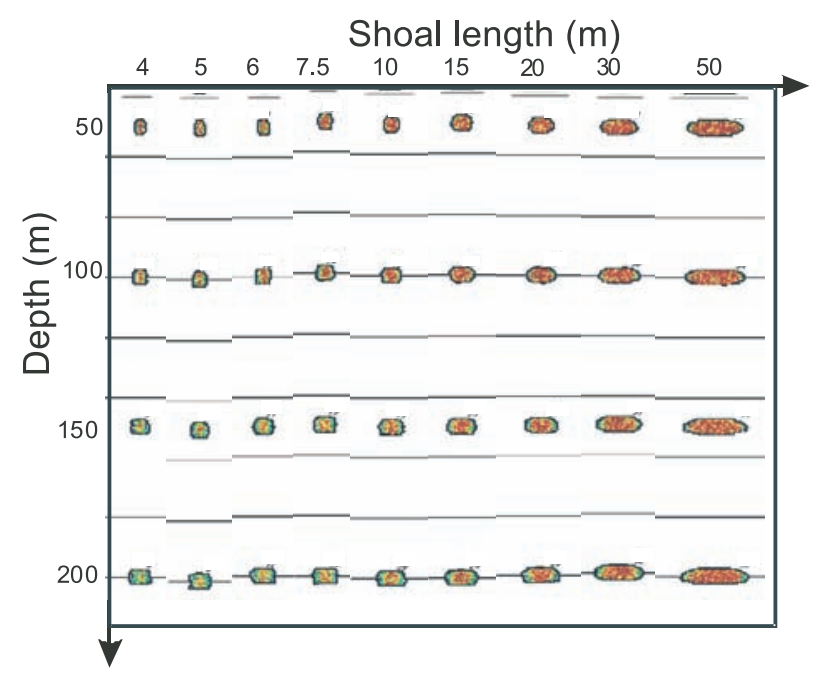

Fig. 5. Echograms of simulated shoals for scenario 3 for $3^{\circ}$ beam width.

depths, it appears that at $50 \mathrm{~m}$ depth and using a $7^{\circ}$ beam, there is no significant bias in measured shoal back-scattering strength $\varepsilon$ for shoal lengths above $10 \mathrm{~m}$ (Table 2, Fig. 6a). In contrast at $200 \mathrm{~m}$ depth, the bias is significant for small shoals, reaching values of $-7.5 \mathrm{~dB}$ for $5 \mathrm{~m}$ long shoals, and only starting to level off at zero for shoals longer than $50 \mathrm{~m}$. The results of scenario 2 show similar bias levels at a given depth as a function of shoal length (Table 3, Fig. 6b). For this scenario several shoals of similar density were simulated. So varying shoal density does not change the relationship between shoal length and bias level which means that the determining parameter is the horizontal dimension compared to the beam width.

For scenario 3 , the beam width was reduced from $7^{\circ}$ to $2^{\circ}$ and $3^{\circ}$. The reduction in bias of the shoal back-scattering strength is most striking at $200 \mathrm{~m}$ depth compared to $50 \mathrm{~m}$ (Fig. 7). At $50 \mathrm{~m}$ depth, underestimation is acceptable for shoal lengths down to 6-7 $\mathrm{m}$ for smaller beam widths. At $200 \mathrm{~m}$, a beam width of $3^{\circ}$ still leads to an attenuation of about $4 \mathrm{~dB}$ for a $6 \mathrm{~m}$ long shoal. However, the smaller beam widths leads to a clear improvement compared to $7^{\circ}$ for small shoal sizes.

The purpose of scenario 4 was to establish a unique relationship between relative shoal size $N b_{i}$ and bias in shoal backscattering strength independent of beam width. The empirical function fitted to the simulated measurements in Figure 8 is:

$$
\hat{\varepsilon}=\frac{-0.6}{N b i-1.1}-0.1
$$


Table 2. Shoal parameter values for simulation scenario 1 with variable dimensions and densities (length, volume, target distance, $\rho$ density, $\sigma_{\text {ag }}$ aggregated back-scattering cross section), but approximately fixed total number of targets $N$ and derived measurements at different depths.

\begin{tabular}{crrcccccc}
\hline$N$ & $\begin{array}{r}\text { Length } \\
(\mathrm{m})\end{array}$ & $\begin{array}{r}\text { Volume } \\
\left(\mathrm{m}^{3}\right)\end{array}$ & $\begin{array}{c}\text { Target } \\
\text { distance } \\
(\mathrm{m})\end{array}$ & $\begin{array}{c}\rho \\
\left(\mathrm{m}^{-1}\right)\end{array}$ & $\begin{array}{c}\sigma_{\mathrm{ag}} \\
\left(\mathrm{m}^{2}\right)\end{array}$ & & \multicolumn{3}{c}{ "measured" $\sigma_{\mathrm{ag}}$} \\
\cline { 5 - 9 } & & & & & $50 \mathrm{~m}$ & $100 \mathrm{~m}$ & $200 \mathrm{~m}$ \\
\hline 9771 & 5 & 65.4 & 0.19 & 148 & 0.291 & 0.166 & 0.110 & 0.053 \\
9709 & 10 & 261.8 & 0.30 & 37 & 0.145 & 0.136 & 0.087 & 0.042 \\
9691 & 20 & 1047 & 0.48 & 9.2 & 0.072 & 0.069 & 0.075 & 0.041 \\
9733 & 30 & 2356 & 0.63 & 4.1 & 0.048 & 0.041 & 0.047 & 0.038 \\
9757 & 40 & 4188 & 0.76 & 2.3 & 0.036 & 0.035 & 0.035 & 0.031 \\
9709 & 50 & 6544 & 0.88 & 1.5 & 0.029 & 0.028 & 0.033 & 0.030 \\
9777 & 75 & 14724 & 1.15 & 0.67 & 0.020 & 0.020 & 0.017 & 0.021 \\
9727 & 100 & 26176 & 1.39 & 0.38 & 0.015 & 0.014 & 0.015 & 0.014 \\
9751 & 200 & 104705 & 2.21 & 0.09 & 0.007 & 0.008 & 0.008 & 0.009 \\
\hline
\end{tabular}

Table 3. Shoal parameter values for simulation scenario 2 and 3 with fixed density $\left(\rho=8 \mathrm{~m}^{1}\right)$, and variable horizontal dimensions $L_{\mathrm{g}}$ and total number of targets $N$ and derived measurements at different depths for scenario $2\left(n_{\text {sh }}\right.$ number of shoals, $S_{\text {hor }}$ shoal surface in horizontal plane, $\sigma_{\text {ag }}$ aggregated back-scattering cross section).

\begin{tabular}{|c|c|c|c|c|c|c|c|c|}
\hline \multirow[t]{2}{*}{$\bar{N}$} & \multirow{2}{*}{$\begin{array}{c}\text { Number } \\
\text { of } \\
\text { shoals }\end{array}$} & \multirow{2}{*}{$\begin{array}{c}\text { Length } \\
\text { (m) }\end{array}$} & \multirow{2}{*}{$\begin{array}{c}\text { Shoal } \\
\text { surface } \\
\left(\mathrm{m}^{2}\right)\end{array}$} & \multirow{2}{*}{$\begin{array}{c}\text { Volume } \\
\left(\mathrm{m}^{3}\right)\end{array}$} & \multirow{2}{*}{$\begin{array}{l}\sigma_{\mathrm{ag}} \\
\left(\mathrm{m}^{2}\right)\end{array}$} & \multicolumn{3}{|c|}{ Scenario 2 "measured" $\sigma_{\mathrm{ag}}$} \\
\hline & & & & & & $50 \mathrm{~m}$ & $100 \mathrm{~m}$ & $200 \mathrm{~m}$ \\
\hline 1932000 & 5600 & 4 & 13 & 42 & 0.013 & 0.007 & 0.004 & 0.002 \\
\hline 1746000 & 3600 & 5 & 20 & 65 & 0.016 & 0.010 & 0.004 & 0.003 \\
\hline 1832500 & 2500 & 6 & 28 & 94 & 0.019 & 0.018 & 0.007 & 0.003 \\
\hline 1883200 & 1600 & 8 & 44 & 147 & 0.024 & 0.016 & 0.014 & 0.006 \\
\hline 1815300 & 900 & 10 & 79 & 262 & 0.031 & 0.025 & 0.018 & 0.011 \\
\hline 1840400 & 400 & 15 & 177 & 589 & 0.047 & 0.037 & 0.040 & 0.020 \\
\hline 1846125 & 225 & 20 & 314 & 1047 & 0.063 & 0.058 & 0.059 & 0.046 \\
\hline 1856900 & 100 & 30 & 707 & 2356 & 0.094 & 0.087 & 0.089 & 0.072 \\
\hline 1860804 & 36 & 50 & 1963 & 6844 & 0.157 & 0.157 & 0.162 & 0.137 \\
\hline 1864272 & 16 & 75 & 4417 & 14724 & 0.236 & 0.209 & 0.210 & 0.231 \\
\hline
\end{tabular}
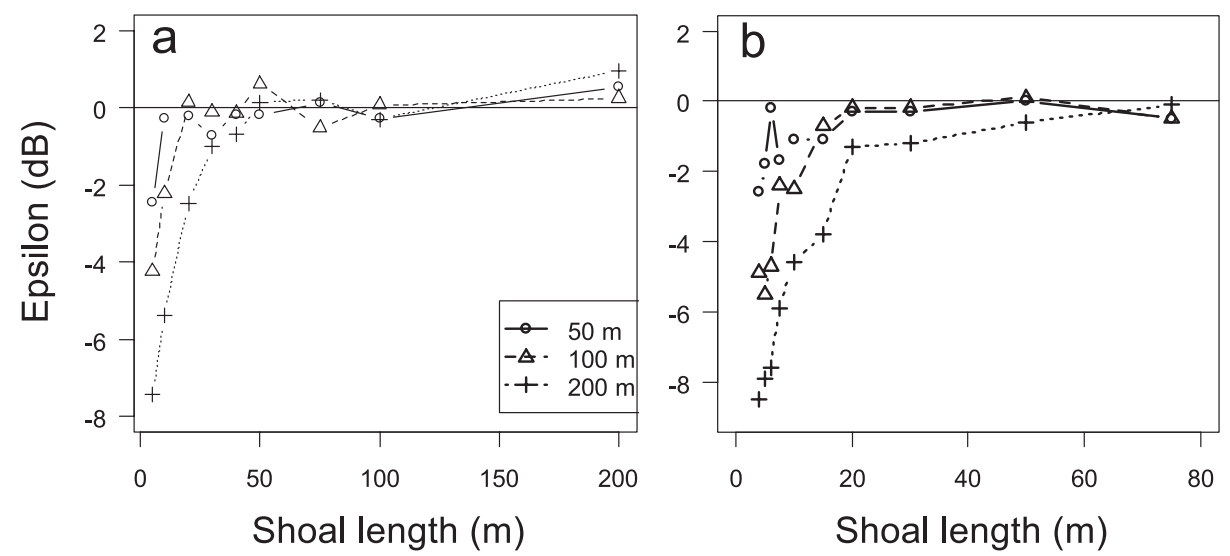

Fig. 6. Impact of horizontal dimension and density on measurement bias $\varepsilon=10 \log _{10}\left(\hat{\sigma}_{\mathrm{ag}}\right)-10 \log _{10}\left(\sigma_{\mathrm{ag}}\right)$ as a function of shoal length at different depths (50, 100 and $200 \mathrm{~m}$ ); a) scenario 1 for a single shoal with variable horizontal dimensions; b) scenario 2 for groups of shoals with different horizontal dimensions but same density and overall same total number of individuals.

This function could be applied to correct measurements for shoals with $N b_{i}$ values above 1.3. The maximum correction will be $3 \mathrm{~dB}$, which represents a significant bias reduction.

\section{Discussion}

Using simulations, the bias in measurements of shoal backscattering strength and thus in the aggregated back-scattering cross-section $\sigma_{\mathrm{ag}}$ of a shoal was found to be substantial for small shoals. The bias was strongly depth dependent. By expressing shoal length relative to beam width, it was possible to obtain a correction function which could be applied for all depths and beam widths, conditional on $N b_{i}>1.3$. A relative shoal size of 1.3 for a beam width of $2-3^{\circ}$ corresponds to the category of smaller shoals encountered in the Bay of Biscay which have shoal lengths of about $10 \mathrm{~m}$ (N. Diner unpublished 
Depth 50 m

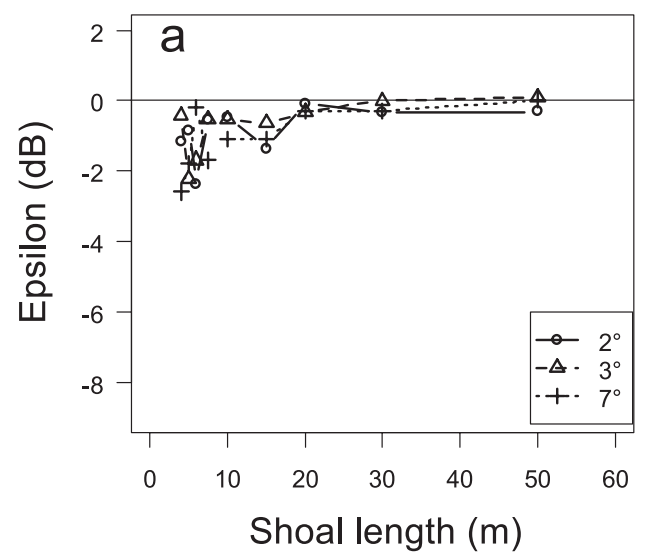

Depth 200 m

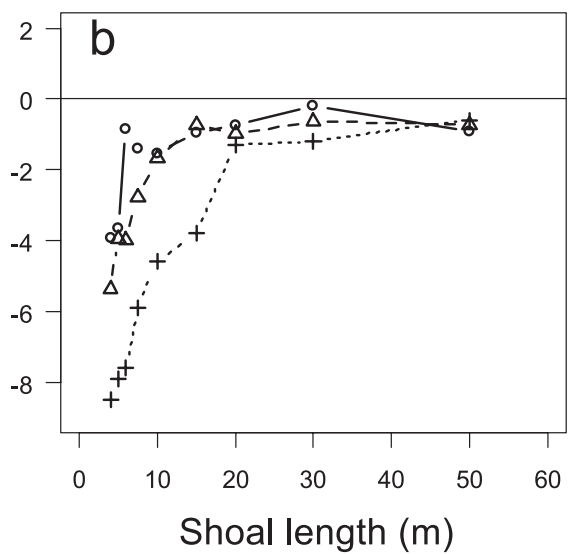

Fig. 7. Impact of beam width on measurement bias $\varepsilon=10 \log \hat{\sigma}_{\mathrm{ag}}-10 \log \sigma_{\mathrm{ag}}$ as a function of shoal length. Results from scenarios 2 and 3 at a) $50 \mathrm{~m}$, b) $200 \mathrm{~m}$.

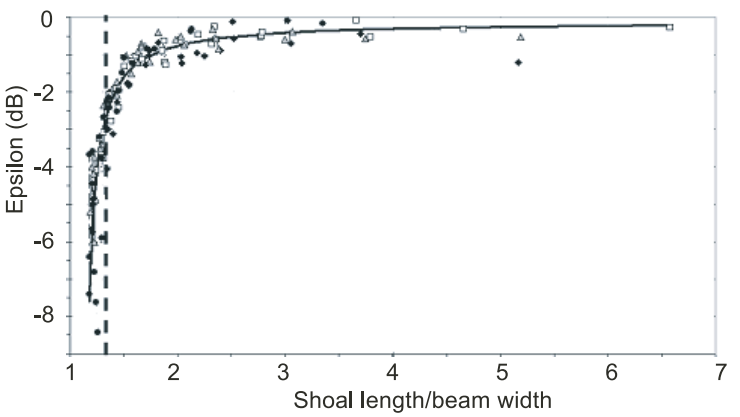

Fig. 8. Measurement bias $\varepsilon=10 \log _{10}\left(\hat{\sigma}_{\mathrm{ag}}\right)-10 \log _{10}\left(\sigma_{\mathrm{ag}}\right)$ as a function of shoal size relative to beam width based on simulations for scenario 4. The vertical line indicates the limit value of 1.3 below which no bias correction is possible.

data). This means shoal back-scattering cross section measurements cannot be corrected if a beamwidth of $7^{\circ}$ or more is used. In this context, it is important to note that when using small beam widths for detecting small shoals, the inter ping distance must be also small so as to reduce variability in the estimates of $N b_{i}$ and $\sigma_{\mathrm{ag}}$. Practically, in case of high vessel speed, high ping rates must be used. Correcting measurements of aggregated back-scattering cross-section can also be relevant for species identification based on morphological and energetic shoal parameters (Scalabrin et al. 1996). For example, the corrections could improve the analysis of different species independently changing depth on a diel or seasonal basis as observed in the Bay of Biscay (Scalabrin and Massé 1993).
Acknowledgements. Much appreciation is due to V. Trenkel (Ifremer), for her significant efforts to refine this paper following the author's retirement. D.A. Demer (NOAA/SWFSC) and two anonymous referees are also gratefully acknowledged for their extensive comments on an earlier version.

\section{References}

Diner N., 2001, Correction on school geometry and density: approach based on acoustic image simulation. Aquat. Living Resour. 14, 211-222.

Diner N., Marchalot C., Berger L., 2003, Echo-integration by school using MOVIES+ software. Ifremer Report DNIS/ESI/DLE/98243.

MacLennan D.N., Fernandes P.G., Dalen, J., 2002, A consistent approach to definitions and symbols in fisheries acoustics. ICES J. Mar. Sci. 59, 365-369.

Muiño R., Carrera P., Petitgas P., Beare D.J., Georgakarakos S., Haralambous J., Iglesias M., Liourzou B., Massé J., Reid D.G., 2003, Consistency in the correlation of school parameters across years and stocks. ICES J. Mar. Sci. 60, 164-175.

Scalabrin C., Diner N., Weill A., Hillion A., Mouchot M.-C., 1996, Narrowband acoustic identification of monospecific fish schools. ICES J. Mar. Sci. 53, 181-188.

Scalabrin C., Massé J., 1993, Acoustic detection of the spatial and temporal distribution of fish shoals in the Bay of Biscay. Aquat. Living Resour. 6, 269-283.

Simmonds E.J., MacLennan D.N., 2005, Fisheries Acoustics. Theory and practice. Blackwell, Oxford.

Weill A., Scalabrin C., Diner N., 1993, MOVIES-B: an acoustic detection description software. Application to shoal species classification. Aquat. Living Resour. 6, 255-267. 